\title{
Distribution of the birds of the Philippines: biogeography and conservation priorities
}

\author{
A. TOWNSEND PETERSON, LISA G. BALL, and KELLY W. BRADY
}

\begin{abstract}
Summary
The Philippine islands hold a concentration of species diversity and endemism of global importance, yet few studies have analyzed biogeographic patterns or attempted to prioritize areas for conservation within the archipelago. We analyzed distributions of 386 species on 28 Philippine islands and island groups, documenting intense concentration of species richness, especially of endemic species, on the two largest islands, Mindanao and Luzon. Factors identified as influencing species richness included island area, maximum elevation, and Pleistocene patterns of connection and isolation. Reserve systems were developed based on heuristic complementarity algorithms, and compared with the existing Integrated Protected Areas (IPAS) system in the country, showing that IPAS is an impressive first step towards protecting avian diversity in the country. Addition of presently proposed reserves on Palawan and Mindoro would make IPAS a near-optimal reserve design, at least at the level of island representation. Important challenges remain, however, with regard to design of reserve systems within islands to represent complete island avifaunas.
\end{abstract}

\section{Introduction}

The Republic of the Philippines is an archipelago in the western Pacific Ocean consisting of more than 700 islands, of which about 470 are larger than $2 \mathrm{~km}^{2}$ (Dickinson et al. 1991). Given the diverse faunas and floras distributed across its islands, and especially owing to intense threat to its high levels of endemism (ICBP 1992), the country has been ranked among the top five globally in terms of conservation priority (Balmford and Long 1994). The subdivided, insular nature of the country constitutes a major challenge to conservation efforts, as choosing a geographic focus is critical to the success or failure of a particular effort. Because much of the country's biodiversity remains in the documentation phase (e.g., Kennedy et al. 1997), efforts to prioritize islands with regard to importance for biodiversity conservation have been compromised; the only study that has taken on this challenge, Hauge et al. (1986), considered a limited sector of the islands in the archipelago (the six best known avifaunistically).

Dickinson et al. (1991) provided a detailed summary of the distribution of each of the 552 species of birds known to occur in the country. For each species, taxonomic information was summarized, and distributions described at least to the level of occurrence on individual islands. Although only minimal analysis was presented with the summary, the information lends perfectly to an analysis of distributional patterns, concentrations of species diversity, and foci of endem- 
ism in the country. We have, in this paper, provided preliminary analyses of each of these themes.

\section{Methods}

Data set

To summarize distributional data for the Philippine avifauna, we compiled island occurrence records for each species from Dickinson et al. (1991) in a database format. Only islands sampled reasonably well were included in the summary (Figure 1 ) and so many for which some data were available were omitted (e.g., Polillo, Guimaras). Islands were, for the most part, considered individually; however, for the smallest and most remote islands, many of which are not well sampled, islands were combined into groups. Islands in these groups were generally separated by shallow (less than $120 \mathrm{~m}$ ) ocean depths, except as indicated by asterisks in the following list. Groups and constituent islands for which occurrence data were available were as follows: Babuyan Group*, Babuyan, Calayan, Camiguin Norte, Dalupiri, Didacas, Fuga; Batan Group*, Batan, Diogo, Ibuhos, Itbayat, Mabudis, North Island, Sabtang, Siayan, Y'ami; Calamianes Group, Bantac, Busuanga, Calauit, Culion, Dicabaito, Linapacan; Sulu Group, Arena, Bancoran, Balukbaluk, Cagayan, Calusa, Cavili, Cayayaveillo, Ciyo, Dandonay, Jessy Beasley Reef, Keenapusan, Malnder, Mahalu, North Islet, South Islet, San Miguel, Sulu, Tubbataha; and Tawitawi Group*, Bahungan, Basbas, Batobato, Bilatan, Bongsaw, Bongao, Bubuan, Manuk Manka, Sanga Sanga, Sibutu, Sipangkat, Si Tangkay, Tandubatu, Tawitawi, Tumindao.

Islands were classed a priori into sets likely connected in the late Pleistocene (Heaney 1985). These groupings were in general based on the $120 \mathrm{~m}$ benthic contour (Heaney 1985, 1991; Figure 1), except in cases where either depths are borderline or the possibility of seafloor depth change exists (e.g., Cuyo and Greater Palawan, Ticao, and Greater Negros). These Pleistocene island groups are referred to as "Greater," connected with the name of the largest or bestknown island in the group.

Island characteristics were summarized based on the Defense Mapping Agency topographic map series and data provided in Stevenson (1977) and Dickinson et al. (1991). These features included island area (summed for island groups), maximum elevation, minimum depth to a larger island or other Pleistocene island group, present-day distance to a larger island or other Pleistocene island group, and Pleistocene distance to a larger island or other Pleistocene island group (Table 1). Pleistocene island definitions were based on the assumption of sea level being $120 \mathrm{~m}$ below present levels in the late Pleistocene (Heaney 1985, 1991). Data on island area and remaining forest cover were obtained from Stevenson (1977) and Dickinson et al. (1991).

Each species that Dickinson et al. (1991) documented for the Philippines, except those listed as hypothetical, was included in the data base. Species were indicated simply as present or absent on each island in the study; no effort was made to take into account limited intra-island geographic distributions or subspecific variation with potential implications for species limits (e.g. Penelopides panini). Species were indicated as breeding or nonbreeding, threatened (T. Brooks, pers. 


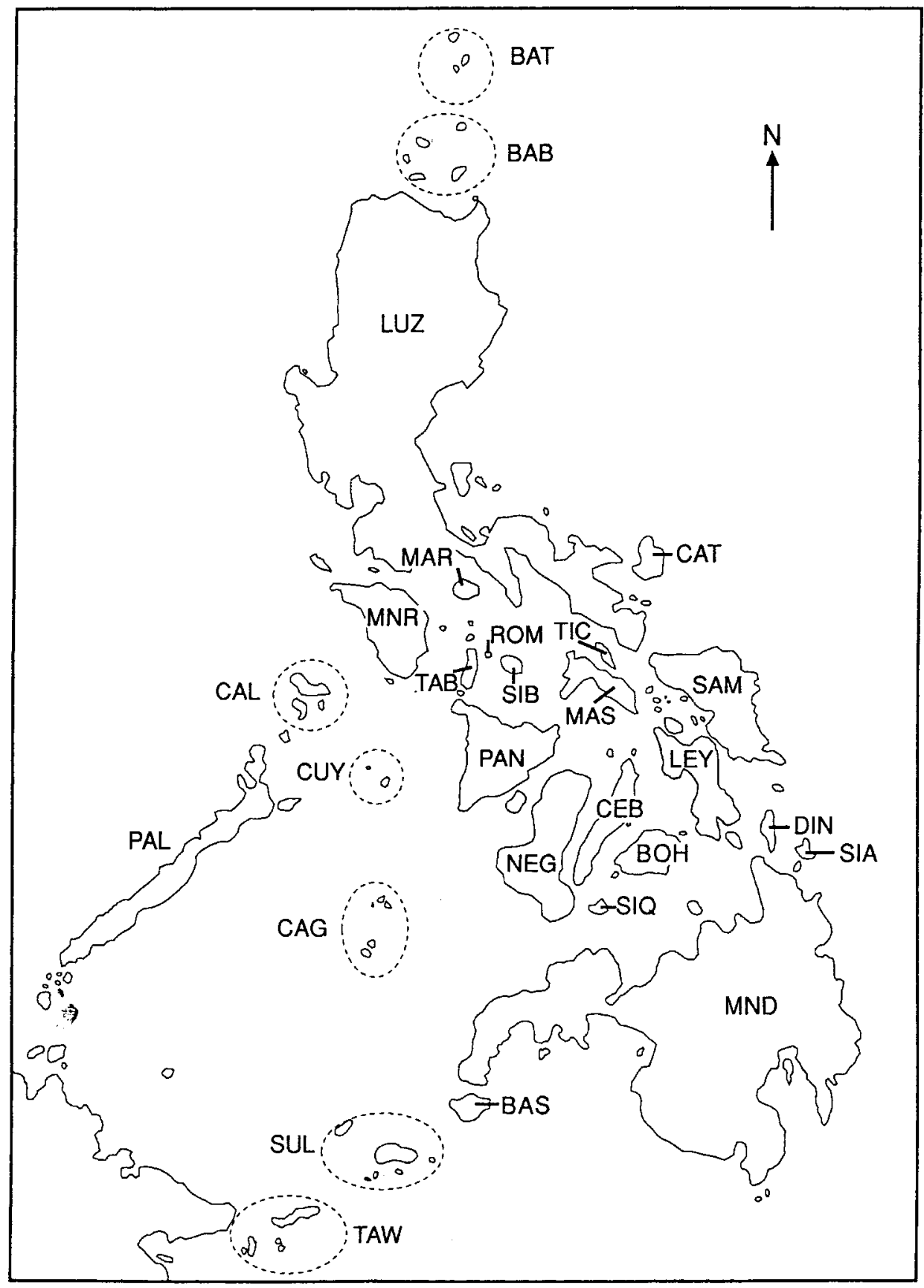

Figure 1. Map of the Philippine archipelago indicating islands included in the study. 
Table 1. Geographic features of 28 islands in the Philippines. Isolation is presented as Pleistocene isolation for Pleistocene islands (e.g., Greater Mindanao), present-day isolation for current islands (e.g., Samar), and present/Pleistocene for islands that did not connect with other islands in the Pleistocene (e.g., Mindoro)

\begin{tabular}{|c|c|c|c|c|c|}
\hline Island & $\begin{array}{l}\text { Area } \\
\left(\mathrm{km}^{2}\right)\end{array}$ & $\begin{array}{l}\text { Percent } \\
\text { forested }\end{array}$ & $\begin{array}{c}\text { Maximum } \\
\text { elevation }(\mathrm{m})\end{array}$ & $\begin{array}{l}\text { Isolation } \\
(\mathrm{km})\end{array}$ & $\begin{array}{l}\text { Minimum } \\
\text { depth }(\mathrm{m})\end{array}$ \\
\hline Greater Mindanao & 120,690 & & & 0.4 & \\
\hline Mindanao & 91,537 & 31 & 2,896 & 13 & 122 \\
\hline Samar & 13,548 & 33 & 2,759 & 1 & 3 \\
\hline Leyte & 10,025 & 11 & 4,298 & 49 & 75 \\
\hline Bohol & 3,625 & 7 & 2,880 & 21 & 24 \\
\hline Basilan & 787 & 23 & 3,316 & 20 & 18 \\
\hline Dinagat & 668 & o & 3,048 & 19 & 57 \\
\hline Siargao & 500 & & 890 & 32 & $150 ?$ \\
\hline Greater Luzon & 115,070 & & & 0.4 & \\
\hline Luzon & 111,520 & 23 & 8,077 & 13 & 122 \\
\hline Catanduanes & 1,823 & 21 & 2,707 & 5 & 53 \\
\hline Marinduque & 1,727 & 2 & 3,796 & 15 & 75 \\
\hline Greater Negros & 32,334 & & & 16 & \\
\hline Negros & 12,528 & 4 & 8,071 & 4 & 549 \\
\hline Panay & 12,303 & 8 & 6,946 & 11 & 12 \\
\hline Cebu & 4,318 & $\mathrm{o}$ & 3,215 & 4 & 51 \\
\hline Masbate & 3,185 & 1 & 2,313 & 36 & 51 \\
\hline Greater Palawan & 12,789 & & & 41 & \\
\hline Palawan & 11,309 & 66 & 6,841 & 149 & 484 \\
\hline Calamianes Group & 1,480 & & 2,149 & 33 & 82 \\
\hline Greater Sulu & 1,339 & & & 2.5 & \\
\hline Sulu Group & 632 & & 2,664 & 118 & 181 \\
\hline Tawitawi & 707 & & 1,145 & 39 & 42 \\
\hline Greater Romblon & 2,161 & & & 10 & \\
\hline Romblon & 1,333 & & 1,457 & 9 & 64 \\
\hline Tablas & 828 & $\mathrm{O}$ & 2,182 & 13 & 274 \\
\hline Mindoro & 10,460 & 8 & 8,478 & $9 / 9$ & 325 \\
\hline Sibuyan & 233 & $\mathrm{o}$ & 6,750 & $28 / 10$ & 274 \\
\hline Ticao & 362 & o & 1,250 & $7 / 0.4$ & 148 \\
\hline Siquijor & 326 & 3 & 1,985 & $22 / 18$ & 366 \\
\hline Cuyo Group & 87 & & 810 & $60 / 94$ & 1188 \\
\hline Cagayan Group & 73 & & 203 & $80 / 94$ & 1188 \\
\hline Babuyan Group & 467 & & 3,570 & $21 / 14$ & 192 \\
\hline Batan Group & 184 & & 3,307 & $151 / 120$ & 1252 \\
\hline
\end{tabular}

comm.), and as endemic or not. Each record in the data set was compiled by one of the authors, and checked by another, allowing detection of most errors. The data set is available on request from the senior author.

This distributional compilation is a powerful tool, in that it includes 552 species' distributions across the Philippine archipelago, a quantity of data so large that individual errors in occurrence records may be of less import. Explicitly acknowledged weaknesses or assumptions inherent in the data set include (1) 
variation in the thoroughness of island surveys, a source of noise in comparisons among islands; (2) no measure of abundance of populations, making distinguishing truly viable populations difficult; and (3) no time dimension, meaning that colonizations and extinctions over the sampling period (approximately 1700present) were not taken into account (Remsen 1994). No effort was made to incorporate distributional or taxonomic data published since the publication of Dickinson et al. (1991), especially the important summary for Sibuyan Island of Goodman et al. (1995).

\section{Analyses}

Species' island occurrences were counted; for endemic species, these counts provided a measure of total range size. Similarities among islands were summarized using Simpson's Index of faunal similarity (Sánchez and López 1988):

$$
S_{a, b}=\frac{N_{a} n_{b}}{\operatorname{MIN}\left(N_{a}, \mathrm{~N}_{b}\right)}
$$

where $N_{a}$ and $N_{b}$ indicate species richness on islands $a$ and $b, N_{a} n_{b}$ represents the number of species shared, and MIN indicates the smaller of the quantities included in the parentheses. Clustering was done using the unweighted pairgroup method (UPGMA).

Nestedness of island faunas was analyzed using programs developed by Atmar and Patterson (1993). ${ }^{1}$ Based in the theory of thermodynamics and entropy, using the analogy of the spatial distribution of water molecules at temperatures between freezing and boiling, departure from perfect nestedness is measured as the degree of disorder inherent in a particular data matrix, expressed as a temperature between $\mathrm{o}$ and 100. Statistical tests are then developed based on comparisons of temperatures of large samples of randomized matrices (Atmar and Patterson 1993).

Relationships between geographic features of the islands and four characteristics of the avifauna (resident species, Philippine endemic species, species endemic to single Pleistocene islands, species endemic to single present-day islands) were analyzed using a relatively new statistical approach, hierarchical partitioning. The usual approach would be multiple regression, which, however, encounters local optima in data, but is not guaranteed to encounter the globally optimal model. Hierarchical partitioning, however, is an exhaustive approach that examines all possible models, and estimates both the independent effects of a particular independent variable and its joint effects with other variables All possible regression submodels are calculated and arranged hierarchically to identify variables having high independent correlations with the dependent variable. In some situations, statistically independent effects can be suppressed by antagonistic joint effects. This technique is designed for such scenarios, converting antagonistic effects into negative joint contributions, effectively unmasking independent contributions, which can be larger than the univariate

\footnotetext{
${ }^{1}$ http://aics-research.com/nestedness/tempcalc.html.
} 
squared partial correlation (for complete details, see Chevan and Sutherland 1991, MacNally 1996; an avian example is given by Watson and Peterson 1999). Although clearly not able to separate correlation from causation, this approach offers an important advantage in that independent and joint effects are distinguished, allowing evaluation of independent contributions from each potential causal variable.

Prioritization of islands for conservation was carried out using a heuristic complementarity algorithm to maximize representation of sets of species (Pressey et al. 1996, Egbert et al. 1998, Peterson et al. 2000). We gave first priority to representation of single-island endemic species, followed by species endemic to the Philippines as a whole, and finally the representation of resident bird species. Threat or endangerment was not included as a prioritization set because the extremely high levels of avian endemism in the country (Dickinson et al. 1991) make all species important in a broad prioritization such as this one; endemism at the level of Pleistocene islands was not included because it and that at the level of individual islands were often redundant, and to reduce the complexity of the complementarity analyses. The procedure was first to choose the island richest in single-island endemic species, then the island that added the most to the total, and so on; ties were broken on the basis of Philippine endemic species, and ties in that quantity were broken based on the representation of resident species. The result is an ordered set of islands on which reserves should be located, yielding a near-optimal representation of the quantities to be maximized.

\section{Results}

\section{Distribution of diversity and endemism}

Distributions of 552 species were summarized in the data base assembled in this study. Of these species, 386 are known to breed in the archipelago, the remaining 166 being winter residents, passage migrants, or vagrants. Breeding bird species are concentrated on the two largest islands, Luzon and Mindanao, which hold 251 and 249 species, respectively (Figure 2a, Table 2). Other large islands (e.g., Negros, Mindoro, Leyte) have breeding avifaunas somewhat reduced (189 or fewer species) in comparison. At the other extreme, small and isolated isolated islands, such as the Cuyo, Cagayan, and Batan groups, have extremely reduced avifaunas $(26,33$, and 52 species, respectively). On the whole, then, avian diversity is distributed unevenly across the archipelago. Patterns of distribution of threatened bird species (Table 2) followed the same general pattern.

One hundred and sixty-nine of the species that breed in the Philippines are found nowhere else, and can be considered endemic to the country. These species also are concentrated on the two largest islands, Luzon and Mindanao (92 and 94 species, respectively), but many are found on smaller islands (Figure $2 \mathrm{~b}$, Table 2). All islands considered in this study held Philippine endemic species, although the remote Cuyo Group held only one, the Philippine Coucal Centropus viridis. A few species (e.g., Ducula pickeringii, Tanygnathus lucionensis) were endemic to the "Philippines" biogeographically, but not politically, strictly speaking, in that they occur marginally on islands off north-eastern Borneo and pertaining to that country politically, and so were not included in counts of endemism. 

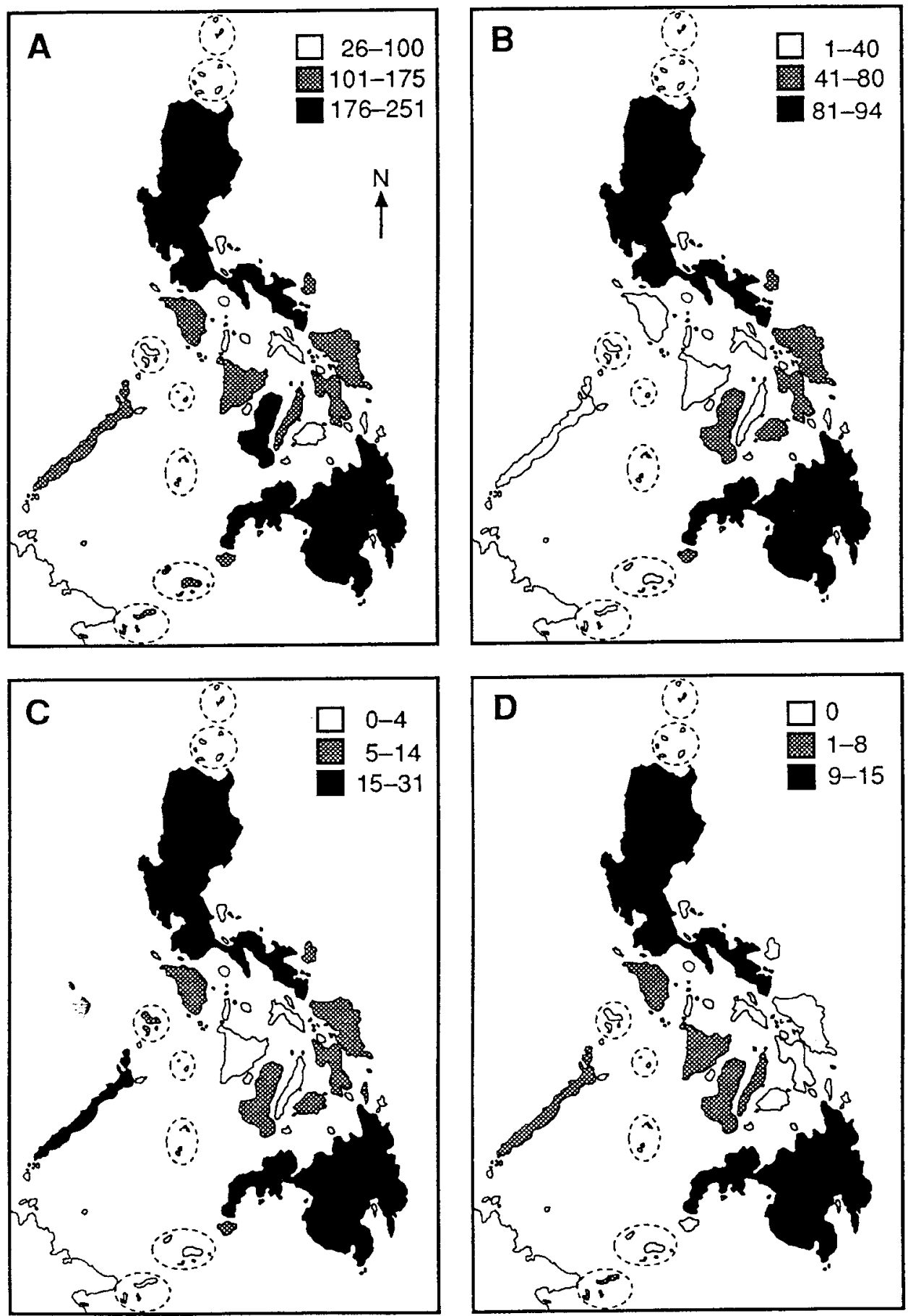

Figure 2. Geographic distribution of species richness and endemism in the Philippine islands: (A) overall species richness, (B) richness of Philippine endemic species, (C) richness of species endemic to single Pleistocene islands, and (D) richness of species endemic to single present-day islands. 
Table 2. Avifaunal characteristics of 28 islands in the Philippines

\begin{tabular}{|c|c|c|c|c|c|c|}
\hline Island & Overall & Residents & $\begin{array}{l}\text { Philippine } \\
\text { endemics }\end{array}$ & $\begin{array}{c}\text { Single } \\
\text { Pleistocene } \\
\text { island } \\
\text { endemics }\end{array}$ & $\begin{array}{c}\text { Single } \\
\text { island } \\
\text { endemics }\end{array}$ & $\begin{array}{c}\text { Threatened } \\
\text { species }\end{array}$ \\
\hline Greater Mindanao & 350 & 260 & 97 & 31 & 15 & 21 \\
\hline Mindanao & 327 & 249 & 94 & 30 & 15 & 19 \\
\hline Samar & 189 & 162 & 61 & 11 & o & 13 \\
\hline Leyte & 186 & 157 & 59 & 11 & o & 12 \\
\hline Bohol & 179 & 139 & 43 & 7 & o & 7 \\
\hline Basilan & 181 & 145 & 42 & 10 & o & 10 \\
\hline Dinagat & 110 & 95 & 38 & 7 & o & 6 \\
\hline Siargao & 75 & 67 & 21 & 5 & o & 4 \\
\hline Greater Luzon & 385 & 251 & 92 & 19 & 13 & 29 \\
\hline Luzon & 384 & 251 & 92 & 19 & 13 & 29 \\
\hline Catanduanes & 140 & 120 & 48 & 6 & o & 5 \\
\hline Marinduque & 109 & 97 & 28 & 2 & o & 4 \\
\hline Greater Negros & 292 & 208 & 60 & 9 & 8 & 20 \\
\hline Negros & 265 & 189 & 54 & 6 & 5 & 15 \\
\hline Panay & 149 & 127 & 28 & 2 & 1 & 5 \\
\hline Cebu & 190 & 138 & 34 & 2 & 2 & 7 \\
\hline Masbate & 114 & 95 & 25 & o & o & 3 \\
\hline Greater Palawan & 251 & 162 & 24 & 16 & 8 & 9 \\
\hline Palawan & 244 & 155 & 24 & 16 & 8 & 8 \\
\hline $\begin{array}{l}\text { Calamianes } \\
\text { Group }\end{array}$ & 108 & 94 & 12 & 8 & o & 4 \\
\hline Greater Sulu & 189 & 130 & 22 & 3 & 2 & 6 \\
\hline Sulu Group & 126 & 100 & 17 & 1 & o & 3 \\
\hline Tawitawi & 162 & 108 & 19 & 3 & 2 & 6 \\
\hline Greater Romblon & 91 & 82 & 14 & o & o & 1 \\
\hline Romblon & 68 & 60 & 8 & o & o & o \\
\hline Tablas & 77 & 71 & 11 & o & o & 1 \\
\hline Mindoro & 234 & 168 & 35 & 5 & 5 & 11 \\
\hline Sibuyan & 100 & 91 & 17 & o & o & 2 \\
\hline Ticao & 101 & 86 & 22 & o & o & 4 \\
\hline Siquijor & 111 & 86 & 14 & o & o & 5 \\
\hline Cuyo Group & 47 & 26 & 1 & o & o & o \\
\hline Cagayan Group & 48 & 33 & 2 & o & o & 1 \\
\hline Babuyan Group & 123 & 65 & 9 & o & o & 1 \\
\hline Batan Group & 106 & 52 & 2 & o & o & o \\
\hline
\end{tabular}

Rather than focusing on endemism at the level of political entities, which can introduce heterogeneity into analyses, a focus on restriction to particular geographic entities can be illuminating (ICBP 1992). In the present case, species restricted to single islands are of particular interest: 51 species are single-island endemics in the Philippines (Tables 2, 3). These species are concentrated on Luzon and Mindanao ( 13 and 15 species, respectively); a few are found on 
Table 3. Single island endemic species found in the Philippines

\begin{tabular}{ll}
\hline Island & Endemic species \\
\hline Mindanao & Trichoglossus johnstoniae, Otus mirus, Actenoides hombroni, Coracina mcgregori, \\
& Leonardina woodi, Rhinomyias goodfellowi, Rhipidura nigrocinnamomea, Basilornis \\
& miranda, Aethopyga primigenius, A. boltoni, Dicaeum nigrilore, D. proprium, \\
& Lophozosterops goodfellowi, Hypocryptadius cinnamomeus, Erythrura coloria \\
Luzon & Turnix worcesteri, Ptilinopus marchei, Otus longicornis, Pitta kochi, Oriolus isabel- \\
& lae, Rhabdornis grandis, Napothera rabori, Stachyris dennistouni, S. whiteheadi, S. \\
& striata, Rhyacornis bicolor, Cettia seebohmi, Rhinomyias insignis, Dryolymnas mir- \\
Palawan & ificus \\
& Polyplectron emphanum, Otus fuliginosus, Hypsipetes palawanensis, Malacocincla \\
& cinereiceps, Malacopteron palawanese, Ptilocichla falcata, Stachyris hypogrammica, \\
Mindoro & Ficedula platenae \\
Negros & Ducula mindorensis, Gallicolumba platenae, Centropus steeri, Otus mindorensis, \\
Cebu & Dicaeum retrocinctum \\
Tawitawi & Ptilinopus arcanus, Gallicolumba keayi, Stachyris nigrorum, Rhinomyias albigularis \\
Panay & Copsychus cebuensis, Dicaeum quadricolor \\
\hline & Gallicolumba menagei, Prioniturus verticalis
\end{tabular}

smaller islands (eight on Palawan, five each on Mindoro and Negros, two each on Cebu and Tawitawi, and one on Panay; Figure 2d, Table 3). In all, almost $60 \%$ (28) of these highly geographically restricted species are found on just two islands.

Recent land connections (8,000-10,000 years ago) among islands can obscure longer-term patterns of connection and isolation of islands in the Pleistocene (Heaney 1985, 1991). Consideration of species found only on single Pleistocene islands, however, shows a clear signal of geographic concentration on a few islands (Figure 2c). Mindanao and Luzon are the best examples (30 and 19 species, respectively), but other islands enter the picture as well, e.g., Palawan (16 species), Samar and Leyte (11), Basilan (10), and even the Calamianes Group (8). Hence, smaller islands are able to hold narrowly endemic species via Pleistocene connections to larger islands. Pleistocene Greater Mindanao, which includes the present-day Mindanao, Bohol, Leyte, Samar, Dinagat, Siargao, and Basilan, holds the richest endemic fauna, with a total of 42 species found on no other Pleistocene island.

\section{Species-area relationships}

The relationship between species richness and island area is a famous component of many theories related to island systems (MacArthur and Wilson 1967). Among Philippine birds, the relationship between resident species richness and island area is tight $\left(y=15.948 x^{0.2475}, R^{2}=0.780\right.$; Figure 3a), making possible prediction of species richness for an island of a given area. Philippine endemic species responded more sharply to increasing island area $\left(y=0.6419 x^{0.4614}, R^{2}=0.623\right)$, suggesting that above a certain island size, such species were likely to dominate an island's avifauna (Figure 3b). Single Pleistocene island endemic species showed a less certain relationship with island area (Figure 3c); in fact, singleisland endemism was negligible below an area threshold of approximately 9,000 $\mathrm{km}^{2}$ (Figure 3d). 

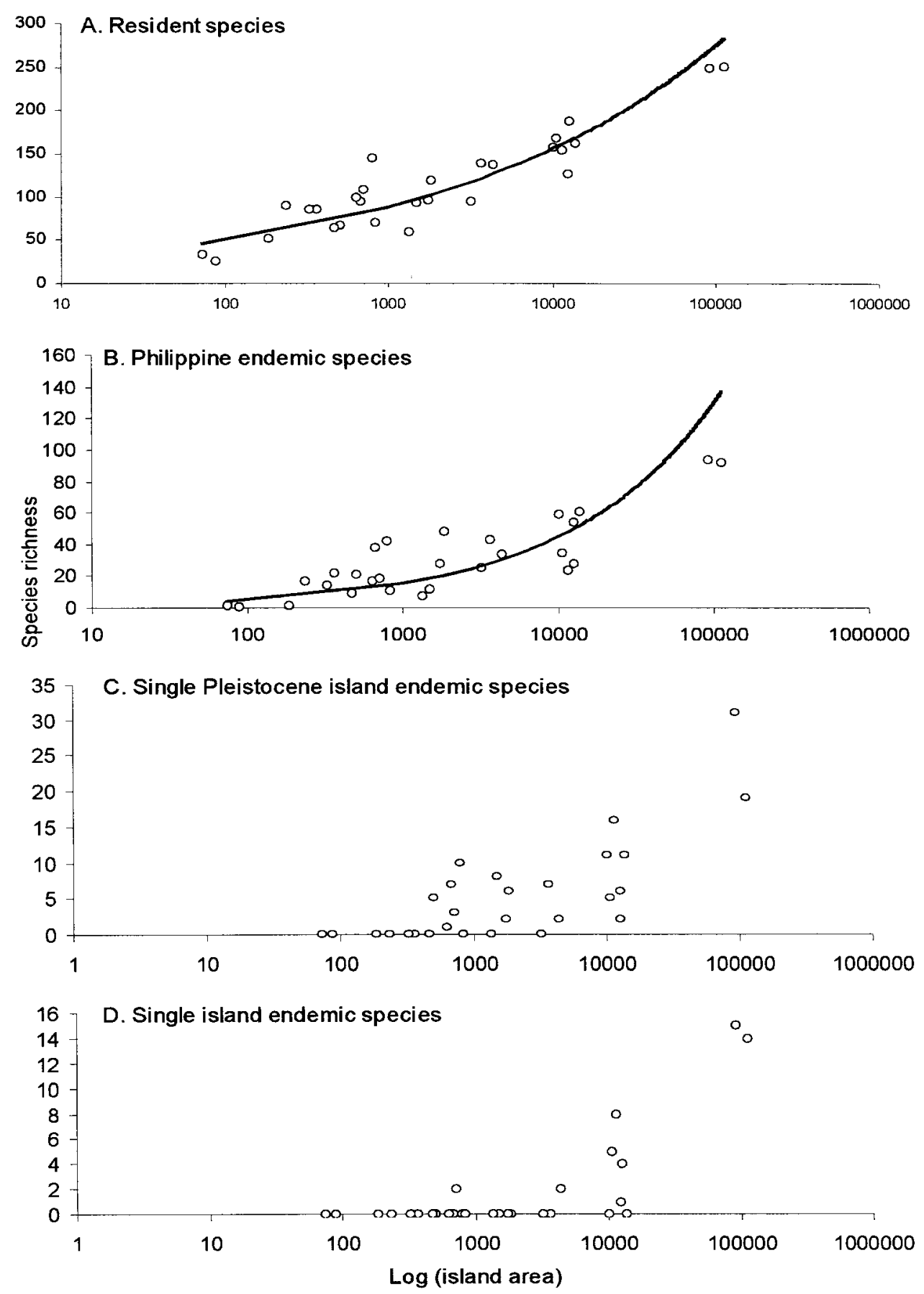

Figure 3. Species-area relationships in components of the Philippine avifauna: (A) all resident species, (B) Philippine endemic species, (C) species endemic to single Pleistocene islands, and (D) species endemic to single present-day islands. Regression details: (A) $y=$ $15.948 x^{0.2475}, R^{2}=0.780$; (B) $y=0.6419 x^{0.4614}, R^{2}=0.623$; (C and D) not calculated owing to predominance of zero values in dependent variable. 
An interesting corollary to these relationships is to explore predictions for past species diversity on islands. As noted previously, many Philippine islands were more extensive in the Pleistocene, with groups connecting into larger islands. For example, in the Pleistocene, Mindanao, Bohol, Leyte, Samar, Dinagat, Siargao, and Basilan, all connected into one larger island, here referred to as Greater Mindanao, which had an area of considerably more than $120,690 \mathrm{~km}^{2}$. Plugging this minimum area estimate into the resident bird species-area relationship, a prediction of 289 species is obtained. Whereas this number is close to the figure present on Mindanao itself (26o species), it is considerably higher than avifauna sizes observed on the smaller islands, in the case of Dinagat by more than 150 species; many additional examples are evident in Table 2 . Hence, to the extent that faunas were continuous across Pleistocene islands, considerable extinction may have occurred in the post-Pleistocene faunal relaxation in the smaller islands that were connected into the large Pleistocene islands.

\section{Island characteristics and diversity}

Given broad variation in levels of diversity and endemism among islands in the Philippines, geographic factors associated with that variation are of interest. We explored the relationship of five geographic dimensions (island area, maximum elevation, Pleistocene isolation, minimum depth, and actual isolation) with four dimensions of species diversity (species richness, richness of Philippine endemics, single Pleistocene endemic species, and single island endemic species; Figure 4). For resident species richness, maximum elevation explained about $40 \%$ of overall variance, area about $30 \%$, and other variables minor amounts. In the three endemism measures examined, island area dominated other factors in the analysis, explaining $38-55 \%$ of total variance. Maximum elevation was also important to overall richness of resident species and levels of endemism, explaining $20-35 \%$ of total variance; other factors examined explained nonsignificant portions of the overall variance.

\section{Avifaunal similarity}

Examining the similarity and difference of avifaunas among islands, several patterns emerged, which interestingly were essentially identical to those described by McGregor (1920). Using cluster analysis to produce a dendrogram representing these patterns (Figure 5), the most distinct islands included in the study were Palawan and the associated Calamianes Group, which have strong Bornean faunal affinities (Heaney 1985). The next most distinctive were the small and remote Babuyan, Batanes, and Cagayan groups. The remaining islands grouped into clear geographic sectors; for instance, the closely geographically associated Catanduanes and Luzon formed a close cluster. Exceptions to this pattern were present: for instance, Samar and Luzon are closely associated geographically, yet did not cluster together. Hence, geographic proximity plays a variable role in determining similarity and difference among faunas.

Using the $120 \mathrm{~m}$ bathymetric contour as an approximation of Pleistocene above-water topography, we compared historical island groups with those identified on the basis of avifaunal similarity (Figure 5). A close correspondence was 

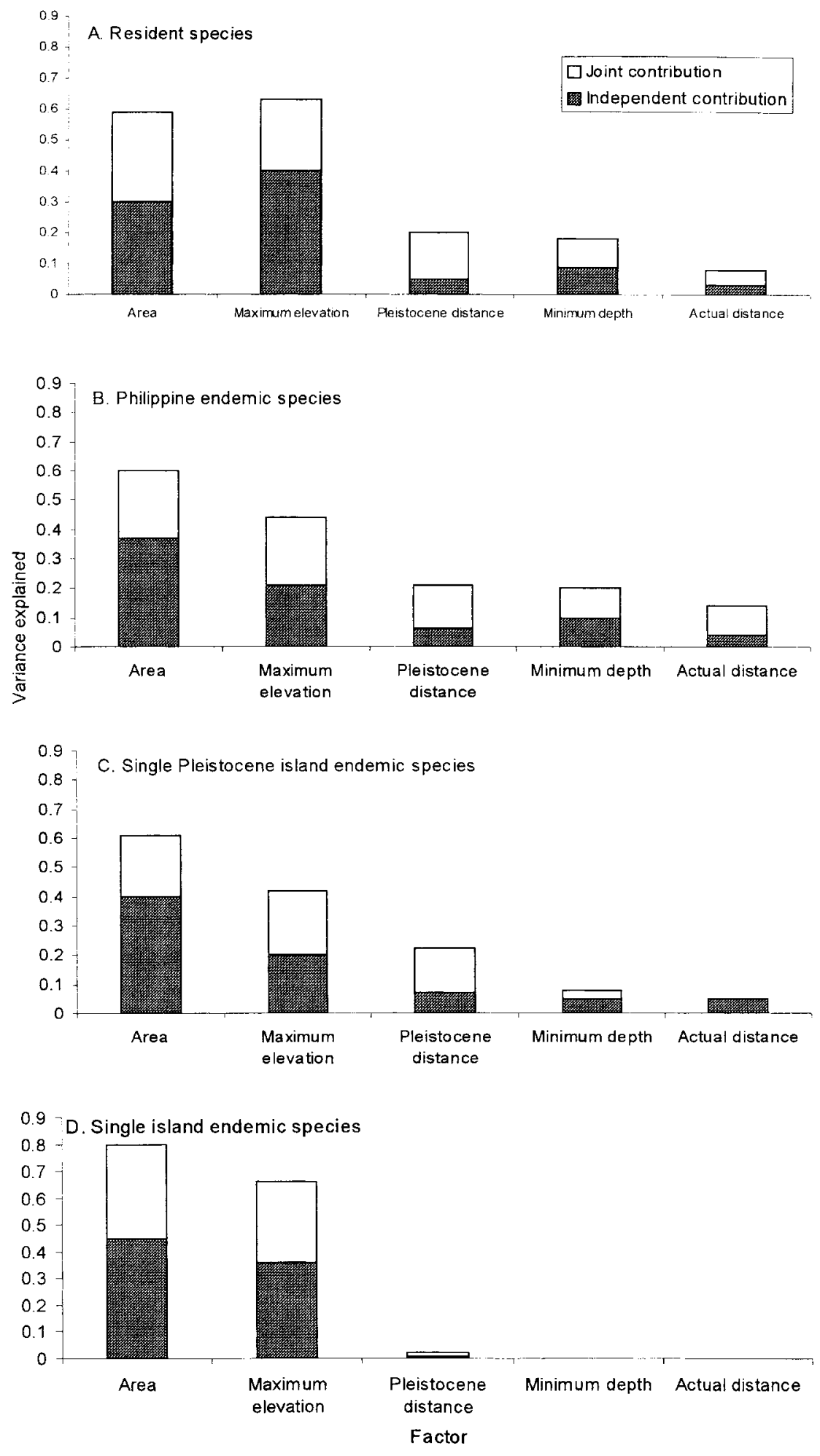


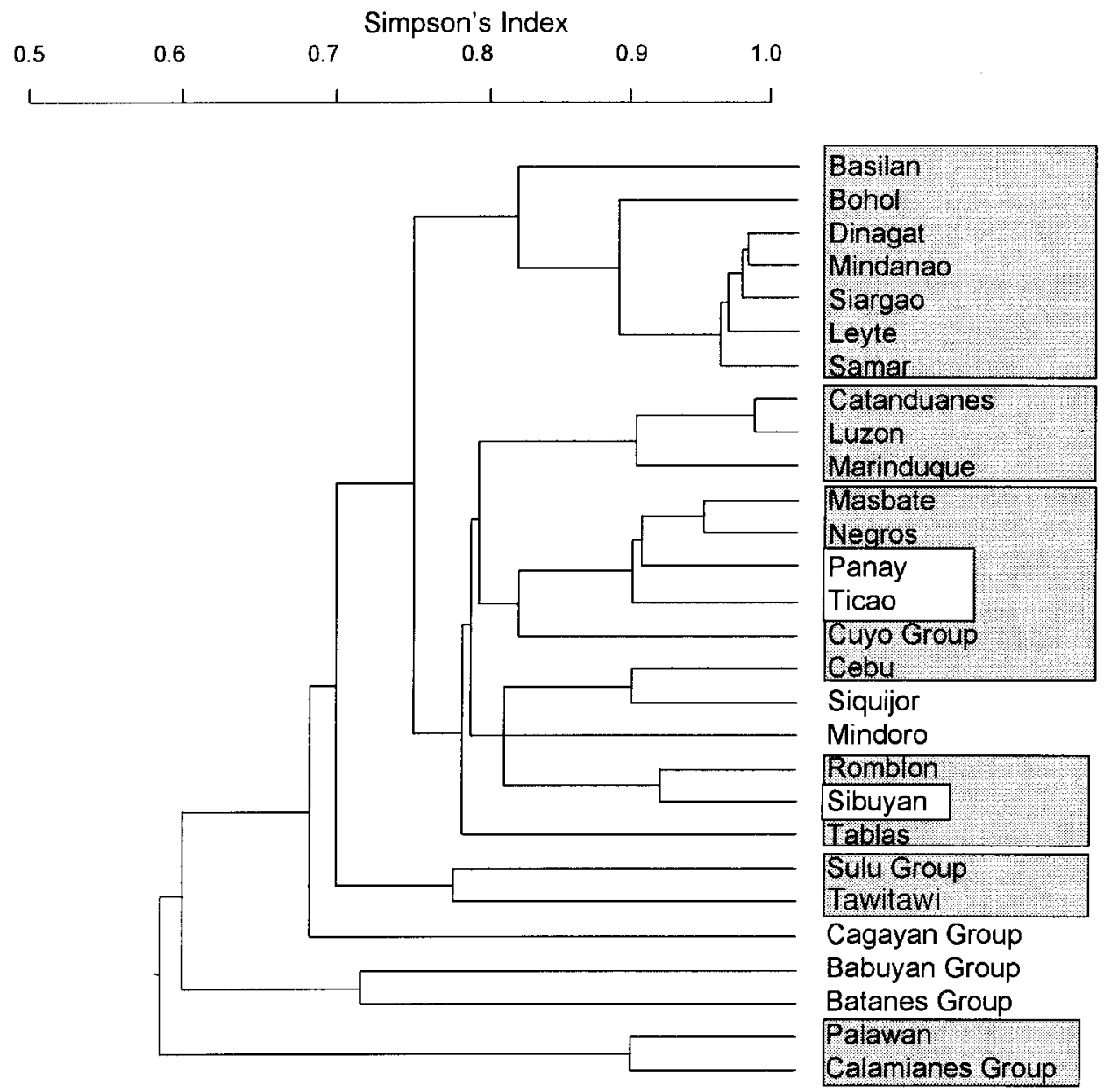

Figure 5. Unweighted pair-group method (UPGMA) clustering of islands based on Simpson's Index of faunal similarity, among all resident bird species. Shadings associated with island groups indicate Pleistocene interconnections among islands, based on the $120 \mathrm{~m}$ bathymetric contour.

found, with Greater Mindanao, Greater Luzon, and Greater Sulu perfectly reflected in avifaunal similarity, as well as a general grouping representing Greater Negros. This correspondence indicates a strong role of historical interconnection in determining faunal composition in the Philippine islands.

Figure 4. Hierarchical partitioning analysis of components of the Philippine avifauna: (A) all resident species, (B) Philippine endemic species, (C) species endemic to single Pleistocene islands, and (D) species endemic to single present-day islands. Areas shaded gray indicate independent contributions of independent variables to the variation of the dependent variable, whereas white areas indicate joint effects. 


\section{Conservation}

Given high levels of endemism combined with rapid rates of destruction of natural habitats, the Philippines have been identified as a top global priority for conservation action (e.g., ICBP 1992, Balmford and Long 1994). After identification as a priority, however, little quantitative information has been assembled to suggest optimal strategies for achievement of conservation objectives. Consequently, based on the data assembled in this study, we carried out several analyses aimed at orienting conservation efforts within the archipelago.

A first step is that of understanding patterns of distribution of species among islands, especially patterns of sharing of species and nestedness of faunas (Patterson 1987). Examining only species of the order Passeriformes because of limitations on matrix size in programs for analysis (Atmar and Patterson 1993), the nested structure of the Philippine avifauna was enormously evident. The matrix is $24.8 \%$ filled, and has a "temperature" of $13.87^{\circ}$; using the randomization algorithm provided in the program, 1000 replicate analyses averaged $69^{\circ} \pm 1.87$ s.d. The probability of this difference occurring by chance alone is approximately $6.14 \times 10^{-44}$, indicating a strong nested structure in the distribution of species on islands in the archipelago. Therefore, conservation strategies must focus on preservation of the very largest faunas to include as many species as possible (but see cautions of Simberloff and Martin 1991 regarding interpretation).

Prioritization of islands for conservation attention can be carried out using complementarity to maximize representation of species (Pressey et al. 1996). On the criterion of single-island endemism, Mindanao ( 15 species), Luzon (13 species), and Palawan (8 species) were the first three islands to enter the system. Negros and Mindoro, each of which holds five single-island endemics, tied for fourth place, but Negros added more species to the total of Philippine endemics, and so entered fourth. Succeeding islands to enter in the system were Mindoro, Tawitawi Group, Cebu, Panay, and one of Samar, Leyte, or Bohol (Figure 6). This ordered set of priorities gives an approximation to the best set of islands for maximizing the stated criteria for any number of islands, from one up to nine. More interestingly, though, all single-island endemic species, as well as all Philippine endemic species, and indeed all species resident in the Philippines can be protected with just nine islands. This reduction of dimensionality provides an important advance in reserve system planning for the country.

Clearly, however, a reserve system cannot simply be created de novo for the Philippines; rather, advances in conservation already in hand must be taken into account, and involved in the "new"reserve system. Heaney (1993) provided a rough summary of sites included in the Integrated Protected Areas (IPAS) program of the Philippine government, as well as of sites proposed for biotic reserve status within the country. We took these two lists (considering only islands, not locations within islands), and examined how they related to our "optimal" design.

The four islands holding current IPAS sites are the Batanes, Luzon, Mindanao, and Negros, with two sites each on Luzon and Mindanao, as might be expected based on their enormous area compared with other islands in the archipelago. A prioritization of these four islands based on complementarity and the three criteria used above places Mindanao first, followed by Luzon, and Negros; the 


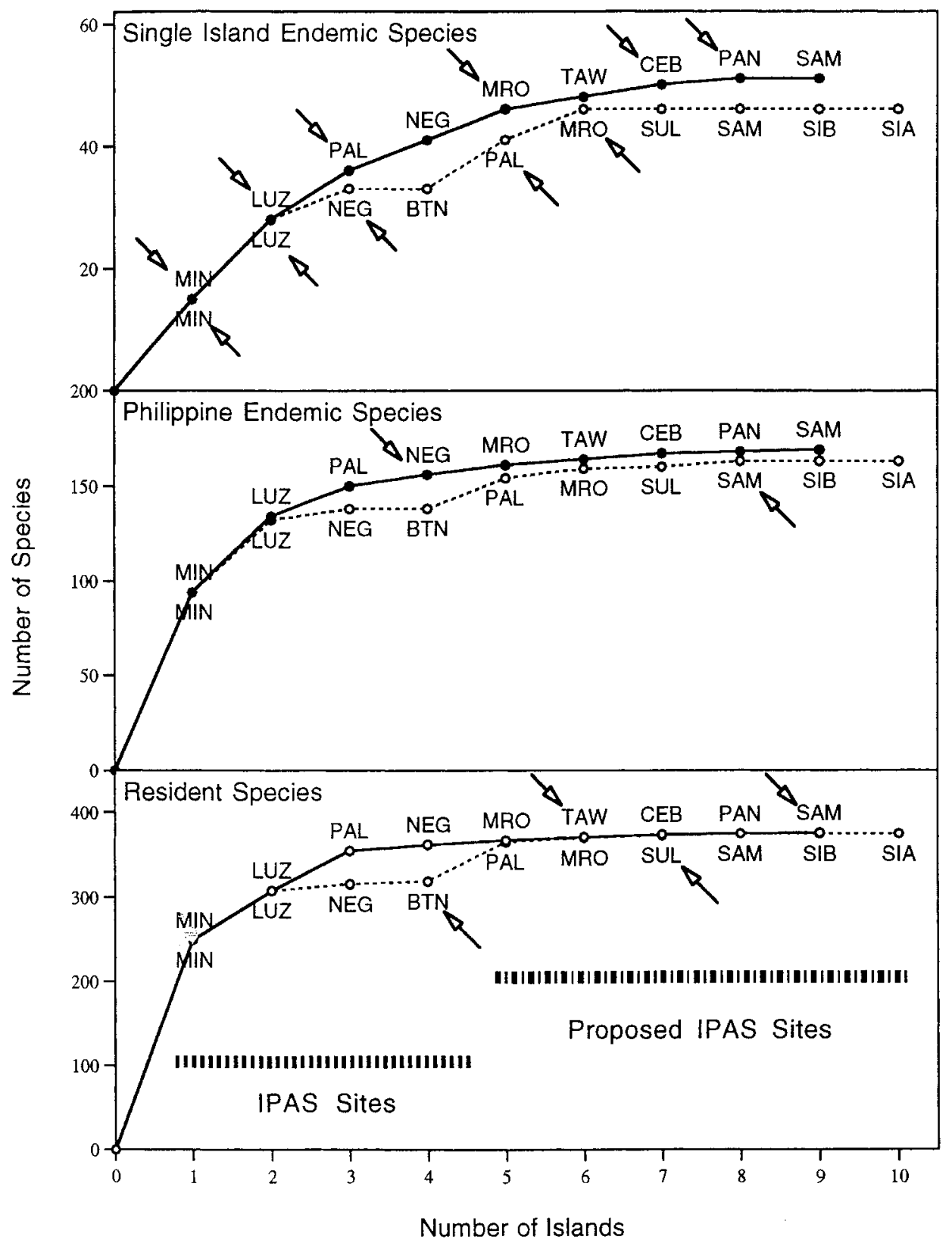

Figure 6. Complementarity approach to assembly of reserve systems for the maximal representation of bird species, based on (top) single-island endemic species, (middle) Philippine endemic species, and (bottom) resident species. See text for detailed explanation of methods. Solid lines indicate application to all islands, whereas dashed lines indicate application first to present (Integrated Protection Area) (IPAS) sites, and then to proposed IPAS sites. Island abbreviations follow Figure 1. 
Batanes reserve enters only under the third criterion (overall species diversity), adding no single-island endemics or Philippine endemics. Extending this analysis to include the proposed sites (Heaney 1993), the first island to enter the system would be Palawan, followed by Mindoro, Sulu, Samar, and Sibuyan; Siargao added no species to the system. Most striking, however, is the close correspondence of the optimal system derived above (Figure 6) with the IPAS and proposed site system, as well as with the results of Hague et al. (1986): differences in overall coverage are slight, making the IPAS and proposed site system an excellent basis for future steps towards conservation of avian diversity in the Philippines.

\section{Discussion}

\section{Species limits and biogeographic patterns}

An important consideration inherent in biodiversity evaluations is the alpha taxonomy - the basic list of species units - on which the study is based (Peterson and Navarro 1999). The existing taxonomy of the birds of the Philippines (Dickinson et al. 1991) greatly underestimates the true diversity of species-level taxa present (Peterson and Navarro unpubl.). Here, clearly, the issue of species concepts arises: the biological species concept (BSC) emphasizes the potential for reproductive interchange among populations (AOU 1998), whereas the phylogenetic (PSC) and evolutionary (ESC) species concepts attempt to assess the evolutionary independence of lineages (Zink and McKitrick 1995). Under both concepts, changes would be in order for the birds of the Philippines: the modern incarnation of the BSC (e.g., AOU 1998) involves recognition of many allopatric forms as species units, whereas the PSC/ESC would recognize as species each unit that shows evidence of independence of evolutionary trajectory.

The Philippines represent a worst-case situation for the BSC, which has always met its most serious challenges in insular situations (Zink and McKitrick 1995). Shifting to an alternative, such as the PSC or ESC, would change the picture of avian diversity in the country drastically (Peterson and Navarro, unpubl.), especially within geographically variable groups such as the Island Thrush Turdus poliocephalus, hornbills (genera Penelopides and Aceros), the Collocalia swiftlets, and several species of flowerpeckers (e.g., Dicaeum anthonyi). Hence, numbers of bird species, particularly endemic species, would increase considerably under an alternative species concept.

An important point is that it is not just numbers of endemic species that change. Taxonomic studies ongoing in Mexico have demonstrated that species concepts strongly influence geographic concentrations of species richness and endemism (Peterson and Navarro 1999). Other, less detailed studies have arrived at the same conclusion (e.g., Hazevoet 1996, Collar 1996). That is, geographic foci under one concept are often de-emphasized under the other, and others highlighted in their place. An important step for Philippine ornithology would be the re-examination of the basic alpha taxonomy.

\section{Faunal relaxation}

The species-area curves for the Philippine islands have implications regarding the past and future of avian diversity in the country. Considering the Pleistocene 
islands of Greater Mindanao, Greater Luzon, Greater Negros, Greater Palawan, Greater Sulu, and Greater Romblon, summing the areas of the component islands as a preliminary estimate of Pleistocene island area, predicted fauna sizes correspond fairly closely to those observed on the largest islands in each group presently ( 289 vs. 249,285 vs. 251,208 vs. 189,166 vs. 155,95 vs. 108 , and 107 vs. 71 species, respectively). Comparing predicted numbers with present-day species richness on the smaller islands in the archipelago, however, suggests that local extinction of species has been considerable since the Pleistocene: the predicted Greater Mindanao total of 252 has declined to just 95 species on Dinagat and 67 on Siargao; the predicted Greater Luzon total of 250 has relaxed to just 97 species on tiny Marinduque. Hence, to the extent that present-day faunas were ubiquitous across Pleistocene islands, local extinction of island populations may have been a dominant process in the Philippines since the Pleistocene.

These extrapolations can be extended to predict future extinctions in the face of the rapid forest destruction in the Philippines (Balmford and Long 1994). Mindanao, for example, has experienced drastic reductions in forest cover, with only approximately $28,376 \mathrm{~km}^{2}$ of $97,923 \mathrm{~km}^{2}$ that could be classified remaining in natural forest vegetation types (Dickinson et al. 1991). Using the species-area relationship for resident species, and making the tenuous assumption that bird species' occurrence is focused in native habitats, if remaining forest were all together in one "island," a predicted final avifauna size would be 201 species, hence predicting the extinction of 48 species from the island's avifauna as relaxation to the new area occurs. These reductions would be more drastic if areas of natural habitat were fragmented, as would clearly be the case. Other islands would experience similar reductions, in fact considerably worse in the cases of islands such as Cebu, Masbate, and Siquijor, which have experienced the most drastic reductions in forest cover.

\section{Conservation priorities}

The present and proposed areas in the IPAS reserve system as summarized by Heaney (1993) represent an advanced and forward-looking reserve scheme. Reserve systems in other countries, when analyzed from the perspective of biodiversity protection, often turn out to be inadequate at best (e.g., Götmark and Nilsson 1992, Peterson et al. 2000) for biodiversity conservation. IPAS, although not without problems, constitutes an important initial step.

A clear first priority for addition to the IPAS system is that of Palawan. Addition of a Palawan reserve is the highest addition priority (Figure 6), essentially allowing the IPAS curve to "catch up" to the optimal system derived in this paper. Mindoro would be the next most important addition. Another important feature, although not assessed in this study, is the inclusion of multiple reserves on Luzon and Mindanao, which are both exceptional concentrations of diversity and endemism, and which are near unique in the archipelago in holding species with limited ranges, and strong among-site differences. With these relatively small adjustments, conservation steps already underway in the Philippines represent near-optimal strategies at the level of island representation.

An additional challenge, however, is that of the design of reserves on individual islands: the analyses presented above are predicated on complete representation of island faunas in reserves. In many cases, this assumption is likely to 
hold: a forested area is likely to hold the species present on that island. However, for at least Mindanao, Luzon, and Negros, some species have restricted distributions within the islands, making choice of reserves critical to the success of conservation strategies. For example, in the case of Mindanao, McGregor's Cuckooshrike Coracina mcgregori is found only in the north-western sector of the island, and does not occur on the southern and eastern massifs, whereas the newly described Lina's Sunbird Aethopyga linaraborae is apparently restricted to the eastern Mindanao massif that includes Mt Mayo (Kennedy et al. 1997). Reserves on these larger and more complex islands will need to be designed so as to include each unique biological element. Problems of effectiveness of reserves - avoiding the "paper park" phenomenon - will also be important.

\section{Acknowledgments}

We would like to thank the participants in the Fall 1995 Biodiversity and Conservation class at the University of Kansas, in the course of which this work was carried out. A very special thanks goes to Larry Heaney for inspiration and advice concerning the biodiversity of the Philippines, as well as to Joe Walsh and David Watson for assistance with data and analyses.

\section{References}

AOU (1998) Check-list of North American birds. Seventh ed. Washington, D. C.: American Ornithologists' Union.

Atmar, W. and Patterson, B. D. (1993) The measure of order and disorder in the distribution of species in fragmented habitat. Oecologia 96: 373-382.

Balmford, A. and Long, A. (1994) Avian endemism and forest loss. Nature 372: 623-624.

Chevan, A. and Sutherland, M. (1991) Hierarchical partitioning. Amer. Statistician 45: 9096.

Collar, N. J. (1996) Species concepts and conservation: A response to Hazevoet. Bird Conserv. Internatn. 6: 197-200.

Dickinson, E. C., Kennedy, R. S. and Parkes, K. C. (1991) The birds of the Philippines: an annotated check-list. London: British Ornithologists' Union (Check-list 12).

Egbert, S. L., Peterson, A. T., Sánchez-Cordero, V. and Price, K. P. (1998) Modeling conservation priorities in Veracruz, Mexico. Pp. 55-63 in S. Morain, ed. GIS in natural resource management: balancing the technical-political equation. Santa Fe, New Mexico: High Mountain Press.

Goodman, S. M., Willard, D. E., and Gonzales, P. C. (1995) The birds of Sibuyan Island, Romblon Province, Philippines, with particular references to elevational distribution and biogeographic affinities. Fieldiana 82: 1-57.

Götmark, F. and Nilsson, C. (1992) Criteria used for protection of natural areas in Sweden 1909-1986. Conserv. Biol. 6: 220-231.

Hague, P., Terborgh, J., Winter, B. and Parkinson, J. (1986) Conservation priorities in the Philippine Archipelago. Forktail 2: 83-91.

Hazevoet, C. J. (1996) Conservation and species lists: taxonomic neglect promotes the extinction of endemic birds, as exemplified by taxa from eastern Atlantic islands. Bird Conserv. Internatn. 6: 181-196.

Heaney, L. R. (1985) Zoogeographic evidence for Middle and Late Pleistocene land bridges to the Philippine Islands. Mod. Quat. Res. Southeast Asia 9: 127-143. 
Heaney, L. R. (1991) A synopsis of climatic and vegetational change in southeast Asia. Climatic Change 19: 53-61.

Heaney, L. R. (1993) Biodiversity patterns and the conservation of mammals in the Philippines. Asia Life Sci. 2: 261-274.

ICBP (1992) Putting biodiversity on the map: priority areas for global conservation. Cambridge, U. K.: International Council for Bird Preservation.

Kennedy, R. S., Gonzales, P. C. and Miranda, H. C. Jr. (1997) New Aethopyga sunbirds (Aves: Nectariniidae) from the island of Mindanao, Philippines. Auk 114: 1-10.

MacArthur, R. H. and Wilson, E. O. (1967) The theory of island biogeography. Princeton, NJ: Princeton University Press.

MacNally, R. (1996) Hierarchical partitioning as an interpretative tool in multivariate inference. Aust. J. Ecol. 21: 224-228.

McGregor, R. C. (1920) Some features of the Philippine ornis with notes on the vegetation in relation to the avifauna. Phil. J. Sci. 16: 361-437.

Patterson, B. D. (1987) The principle of nested subsets and its implications for biological conservation. Conserv. Biol. 1: 323-334.

Peterson, A. T. and Navarro, A. G. (1999) Alternate species concepts as bases for determining priority conservation areas. Conserv. Biol. 13:427-431.

Peterson, A. T., Egbert, S. L., Sánchez-Cordero, V. and Price, K. P. (200o) Geographic analysis of conservation priorities using distributional modeling and complementarity: endemic birds and mammals in Veracruz, Mexico. Biol. Conserv. 93: 85-94.

Pressey, R. L., Possingham, H. P. and Margules, C. R. (1996) Optimality in reserve selection algorithms: when does it matter and how much? Biol. Conserv. 76: 259-267.

Remsen, J. V. Jr. (1994) Use and misuse of bird lists in community ecology and conservation. Auk 111: 225-227.

Sánchez, O. and López, G. (1988) A theoretical analysis of some indices of similarity as applied to biogeography. Folia Entomol. Mex. 75: 119-145.

Simberloff, D. and Martin, J.-L. (1991) Nestedness of insular avifaunas: Simple summary statistics masking complex species patterns. Orn. Fenn. 68: 178-192.

Stevenson, A. J. (1977) Webster's new geographical dictionary. Springfield, MA Merriam.

Watson, D. M. and Peterson, A. T. (1999) Determinants of diversity in a naturally fragmented landscape: humid montane forest avifaunas of Mesoamerica. Ecography 22: 582589.

Zink, R. M. and McKitrick, M. C. (1995) The debate over species concepts and its implications for ornithology. Auk 112: 701-719.

A. TOWNSEND PETERSON and LISA G. BALL

Natural History Museum and Department of Ecology and Evolutionary Biology, The University of Kansas, Lawrence, Kansas 66045, U.S.A.

KELLY W. BRADY

Department of Ecology and Evolutionary Biology, The University of Kansas, Lawrence, Kansas 66045, U.S.A. 